\title{
Folic acid supplementation improves cognitive function: A systematic review
}

\author{
I Putu Eka Widyadharma, Eric Hartono Tedyanto, Anak Agung Ayu Putri Laksmidewi, \\ Made Oka Adnyana, Dewa Putu Gde Purwa Samatra \\ Department of Neurology, Sanglah General Hospital, Bali, Indonesia \\ Udayana University, Bali, Indonesia
}

\begin{abstract}
Introduction. The most common type of dementia is Alzheimer's disease (AD). AD is characterized by loss of memory and cognitive impairment. In epidemiological studies, low folate could disturb vitamin B12 absorption, which leads to the inflammatory process, and it explains the association between both vitamins and Alzheimer's disease.

Material and methods. We did a systematic search through PubMed and Embase according to the PRISMA protocol. We included studies published in the last 5 years (from 2015 to June 2020). Data will be extracted by two reviewers. We assess the quality of studies using JADAD Scale for randomized-controlled trials.

Results. We found 426 journals in our search strategy. In the end, 2 studies met the eligibility criteria and were included in this review. These two randomized controlled trials revealed that folic acid improved cognitive function in Alzheimer's disease $(p<0.05)$ and mild cognitive impairment $(p=0.028)$.

Discussion. In this systematic review, we found that daily folic acid supplements could improve cognitive function in patients with Alzheimer's disease and mild cognitive impairment. The exact mechanism is unknown, but it is believed that folic acid supplementation improves cognitive function by reducing the levels of peripheral inflammatory cytokines

Conclusion. Daily oral folic acid supplemental (400 $\mu \mathrm{g}$ and $1.2 \mathrm{mg})$ for 6-12 months improves cognitive function in Alzheimer's disease and mild cognitive impairment.
\end{abstract}

Keywords: folic acid, cognitive function, Alzheimer's disease

\section{INTRODUCTION}

The most common type of dementia is Alzheimer's disease (AD). AD is characterized by loss of memory and cognitive impairment. AD is a neurodegenerative disease and worsens by age, which leads to death within 7-10 years of diagnosis $(1,2)$. The pathogenesis is still unclear, but it is expected that the inflammatory process plays a role in the mechanism of $\mathrm{AD}$ and mild cognitive impairment (3).

Folate is a water-soluble B vitamin. In epidemiological studies, low folate could disturb vitamin B12 absorption, which leads to an inflammatory process, and it explains the association between both vitamin and Alzheimer's disease (4). Folate, B12, and B6 vitamins support process in the remethylation of homocysteine to methionine. Homocysteine serum levels is associated with AD and cognitive impairment. High homocysteine levels lead to have an impact on cerebral pathology, neurotoxic effects, influence on neurofibrillary tangle, and deposit of $\beta$-amyloid, which may play a role in mechanism of AD and cognitive impairment (5). Some studies have also reported that folate levels are lower in patients with Alzheimer's disease than in normal patients (6).

Many clinicians prescribed folate and other B vitamin supplement for $\mathrm{AD}$ and cognitive impairment patients, but the effectiveness remains controversial (7). The purpose of making this systematic review to identify whether folic acid supplementation improves cognitive function or not. 


\section{MATERIAL AND METHODS}

\section{Searching and screening}

We did a systematic search through PubMed and Embase according to the PRISMA protocol. We included studies published in the last 5 years (from 2015 to June 2020). We use two keywords - "folic acid"; "cognitive function" - on the database search.

\section{Inclusion and exclusion criteria}

We included published articles with randomized-controlled trial design. We exclude articles that are cohort, case-control, cross-sectional, descriptive studies, case reports, or qualitative studies. Non-English articles were also excluded. Eligibility criteria in the PICOS model are presented in Table 1.

\section{Data extraction}

Data will be extracted by two reviewers. The disagreement data from two reviewers will be resolved by the third reviewer.

\section{Quality assessment}

We assess the quality of studies using JADAD Scale for randomized-controlled trials. The quality assessment table can be seen in Table 2 .

TABLE 1. Eligibility criteria in PICOS model

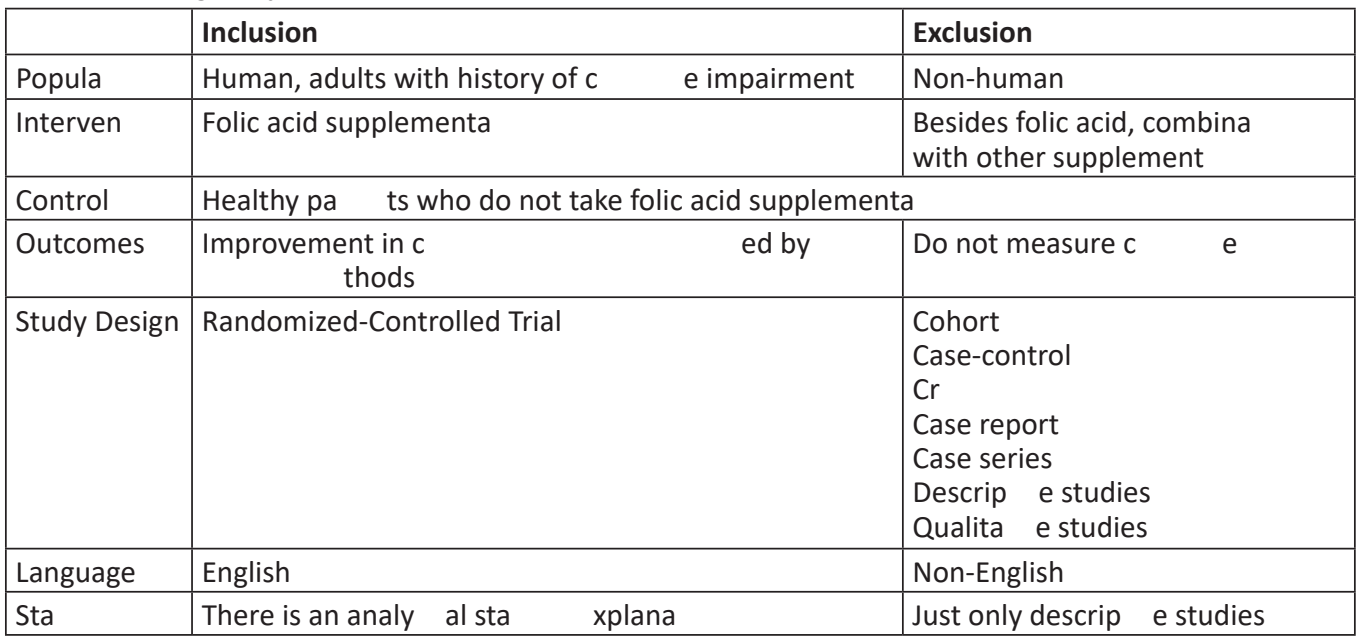

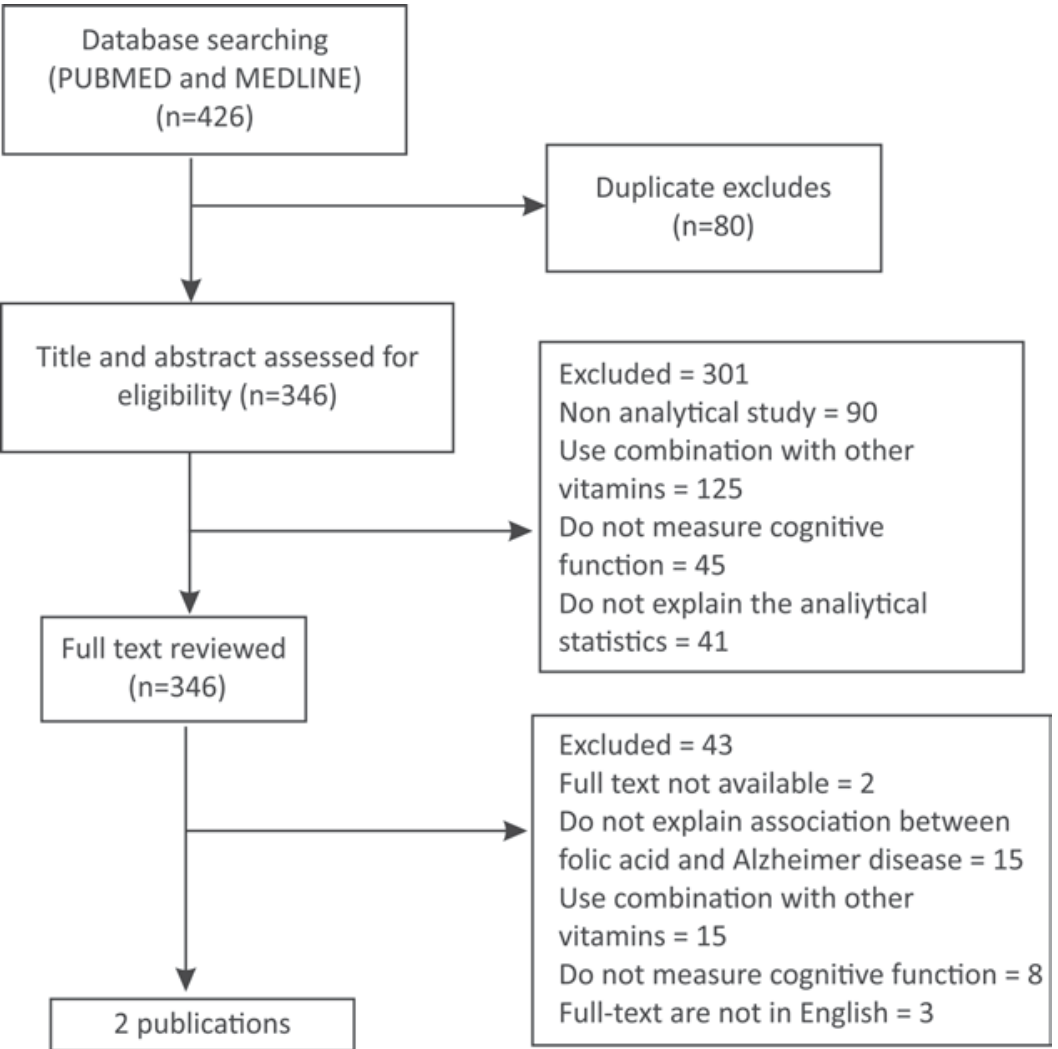




\section{RESULTS}

\section{Study selection}

We found 426 journals in our search strategy. At the first screening, we excluded 80 duplicated journals. Second, the title and abstract were reviewed based on the eligibility criteria, as many as 301 were excluded, 45 remained. At the third screening, full-text was reviewed, as many as 43 journals were excluded. Finally, 2 studies met the eligibility criteria and were included in this review. The flow diagram of the systematic searching strategy is shown in Figure 1.

\section{Quality assessment}

The overall quality of the studies was good. We used JADAD Scale to assess the quality of our studies. The two studies are randomized, blinded, and described the subject withdrawal. The quality assessment can be seen in Table 2 (JADAD Scale).

TABLE 2. JADAD Scale. Quality assessment for randomized-controlled trial

\begin{tabular}{|l|c|c|c|c|}
\hline $\begin{array}{l}\text { Author, } \\
\text { years }\end{array}$ & Randomization & Blinding & Withdrawals & Total \\
\hline Chen, 2016 & 2 & 2 & 1 & $5 / 5$ \\
\hline Ma, 2016 & 2 & 2 & 1 & $5 / 5$ \\
\hline
\end{tabular}

\section{Study report characteristics}

These two randomized-controlled trials were conducted in China. The total participants ranged from 121 to 152 patients. Chen revealed that Mean MMSE improved in the intervention group compared to the control group ( $\mathrm{p}<0.05)$. Ma revealed that daily $400 \mu \mathrm{g}$ of folic acid for 12 months improves cognitive function measured by many cognitive tests, such as Full-Scale IQ Test $(\mathrm{p}=0.028)$, Information $(\mathrm{p}=0.031)$, and Digit
Span $(\mathrm{p}=0.009)$. More info about study characteristics can be seen in Table 3 .

\section{DISCUSSION}

In this systematic review, we found that daily folic acid supplements could improve cognitive function in patients with Alzheimer's disease and mild cognitive impairment. The exact mechanism is unknown, but it is believed that folic acid supplementation improves cognitive function by reducing the levels of peripheral inflammatory cytokines (9).

\section{Peripheral inflammatory cytokine levels and cognitive impairment and dementia}

Peripheral inflammatory cytokines play a role in developing cognitive impairment and dementia. Inflammatory cytokines, such as IL-6, IL-1 $\beta$, and TNF- $\alpha$ can cross the blood-brain barrier, suggesting that it may have a direct effect on the brain. Peripheral cytokines have been associated with a reduced volume of hippocampal and memory performance $(10,11)$.

\section{Folic acid supplementation on peripheral inflammatory cytokine levels}

Homocysteine is a risk factor in developing dementia and cognitive impairment. High homocysteine levels lead to have an impact on cerebral pathology, neurotoxic effects, influence on the neurofibrillary tangle, and deposit of $\beta$-amyloid, which may play a role in the mechanism of AD and cognitive impairment (5). Homocysteine is also associated with peripheral inflammation in animal studies and human. Folate promotes the remethylation of homocysteine to methionine. Some studies suggested that daily folic acid supplementation

TABLE 3. Study characteristics

\begin{tabular}{|c|c|c|c|c|c|}
\hline Author & Design & Subject & Intervention & Control & Result \\
\hline $\begin{array}{l}\text { Chen, } 2016 \\
\text { (8) }\end{array}$ & RCT & $\begin{array}{l}121 \text { pa ts } \\
\text { with possible } \\
\text { Alzheimer's } \\
\text { disease, with } \\
\text { MMSE score } \\
\text { between } 3 \text { and } 26\end{array}$ & $\begin{array}{l}61 \text { Alzheimer's disease } \\
\text { pa ts that received } \\
1.25 \mathrm{mg} / \mathrm{d} \text { folic acid } \\
\text { supplementa } \\
\text { donepezil medica } \\
\text { completed 6-months } \\
\text { follow-up }\end{array}$ & $\begin{array}{l}60 \text { with Alzheimer's } \\
\text { disease and } \\
\text { donepezil } \\
\text { medica } \\
\text { completed } \\
\text { 6-months follow-up }\end{array}$ & $\begin{array}{l}\text { Mean MMSE improved in interven } \\
\text { group compared to control group } \\
(p<0.05) \text {. Folic acid has a role in } \\
\text { improving c t } \\
\text { with Alzheimer's disease. }\end{array}$ \\
\hline $\begin{array}{l}\text { Ma, } 2016 \\
\text { (9) }\end{array}$ & RCT & $\begin{array}{l}152 \text { pa ts with } \\
\text { mild c e ? } \\
\text { impairment, } \\
\text { iden y } \\
\text { Petersen's criteria }\end{array}$ & $\begin{array}{l}77 \mathrm{MCl} \text { pa ts that } \\
\text { received } 400 \mu \mathrm{g} / \mathrm{d} \text { folic } \\
\text { acid tablet for } 12 \text { months }\end{array}$ & $\begin{array}{l}75 \text { pa ts with } \\
\text { conven } \\
\text { therapy for } 12 \\
\text { months }\end{array}$ & \begin{tabular}{|l} 
Daily $400 \mu \mathrm{g}$ folic acid for 12 months \\
improves c ed? \\
by many c e Eests, such as Full- \\
Scale IQ Test ( $p=0.028)$, Informa \\
( $p=0.031)$, and Digit Span $(p=0.009)$
\end{tabular} \\
\hline
\end{tabular}


reduced homocysteine concentration in plasma. Therefore, it is believed that folic acid may have a role in cognitive improvement by reducing the homocysteine concentration $(12,13)$. Studies from $\mathrm{Ma}$ also revealed that consuming folic acid supplementation $(400 \mu \mathrm{g})$ in the 12-months period, decreased the IL-6, TNF- $\alpha$, and A $\beta-42$ ( $\beta$-amyloid) levels.

\section{Folic acid supplementation improves cognitive function}

In this systematic review, daily oral folic acid supplements can significantly improve cognitive function. It is similar to the results of a FACIT trial that daily oral $800 \mu \mathrm{g}$ folic acid for 36 months improves the performance on a test that measures the memory function (14). Study from Chen, involved 61 Alzheimer's disease patients with MMSE score between 3 and 26 that received $1.25 \mathrm{mg} / \mathrm{d}$ folic acid supplementation + donepezil medication, completed 6-months follow-up, revealed that mean MMSE improved in the intervention group (folic acid and donepezil) compared to the control group (donepezil only) $(\mathrm{p}<0.05)(8)$. Study from Ma, involved $77 \mathrm{MCI}$ patients that received $400 \mu \mathrm{g} / \mathrm{d}$ folic acid tablet for 12 months, revealed that daily $400 \mu \mathrm{g}$ folic acid for 12 months improves cognitive function measured by many cognitive tests, such as Full-Scale IQ Test $(p=0.028)$, Information $(\mathrm{p}=0.031)$, and Digit Span $(\mathrm{p}=0.009)$. Patients with folic acid have a better performance on Information Test and Digit Span test compared to control group (9).

\section{REFERENCES}

1. Alzheimer's \& Dementia. Basics of Alzheimer's Disease. Alzheimer's Assoc Rep. 2015.

2. Masters CL, Cappai R, Barnham KJ, Villemagne VL. Molecular mechanisms for Alzheimer's disease: Implications for neuroimaging and therapeutics. Journal of Neurochemistry. 2006;97(6):1700-25.

3. Chouliaras L, Mastroeni D, Delvaux E, Grover A, Kenis G, Hof PR, et al. Consistent decrease in global DNA methylation and hydroxymethylation in the hippocampus of Alzheimer's disease patients. Neurobiol Aging. 2013;34(9):2091-9.

4. Chen H, Liu S, Ji L, Wu T, Ma F, Ji Y, et al. Associations between Alzheimer's Disease and Blood Homocysteine, Vitamin B12, and Folate: A Case-Control Study. Curr Alzheimer Res. 2015; 12(1):88-94

5. Moretti R, Caruso P, Matteo D Ben, Conti C, Gazzin S, Tiribelli C. Vitamin D, homocysteine, and folate in subcortical vascular dementia and Alzheimer dementia. Front Aging Neurosci. 2017; 9:169.

6. Shah R. The role of nutrition and diet in Alzheimer disease: $A$ systematic review. Journal of the American Medical Directors Association. 2013;14(6):398-402.
Decreased memory function has been associated with hippocampal lesions. Hippocampal plays an important role in short and long-term memory. Low-grade peripheral inflammation may cause hippocampal change, including hippocampal volume. Hippocampal also has a huge number of receptors for inflammatory cytokines, such as IL-6 and IL-1 $\beta$ in the brain. As mentioned above, folic acid supplement decreased IL-6, TNF- $\alpha$, and other inflammatory cytokines. Thus, folic acid supplement could be potentially improves the cognitive function via reducing levels of peripheral inflammatory cytokines (15-17).

This review has some limitations. First, the number of studies included in this review was small (only 2 studies). Second, there were different diagnostic criteria to diagnose cognitive impairment (MMSE and Full Scale-IQ, Information, and Digit Span test). But hopefully, this review could give update information about association between folic acid supplement and cognitive function.

\section{CONCLUSIONS}

Daily oral folic acid supplementation (400 $\mu \mathrm{g}$ and $1.2 \mathrm{mg}$ ) for 6-12 months improves cognitive function in Alzheimer's disease and mild cognitive impairment. More studies about the association between folic acid and cognitive function are needed.

\section{Acknowledgement}

All authors have equal parts in doing this article.

7. Zheng $\mathrm{M}$, Zhang $\mathrm{M}$, Yang J, Zhao S, Qin S, Chen $\mathrm{H}$, et al. Relationship between blood levels of methyl donor and folate and mild cognitive impairment in Chinese patients with type 2 diabetes: A case-control study. J Clin Biochem Nutr. 2014;54(2):122-128.

8. Chen H, Liu S, Ji L, Wu T, Ji Y, Zhou Y, et al. Folic Acid Supplementation Mitigates Alzheimer's Disease by Reducing Inflammation: A Randomized Controlled Trial. Mediators Inflamm. 2016;59(1):214-6.

9. Ma F, Wu T, Zhao J, Song A, Liu H, Xu W, et al. Folic acid supplementation improves cognitive function by reducing the levels of peripheral inflammatory cytokines in elderly Chinese subjects with MCl. Sci Rep. 2016;6:37486.

10. Morgan AR, Touchard S, Leckey C, O'Hagan C, Nevado-Holgado AJ; NIMA Consortium, Barkhof F, Bertram L, Blin O, Bos I, Dobricic V, Engelborghs S, Frisoni G, Frölich L, Gabel S, Johannsen P, Kettunen P, Kłoszewska I, Legido-Quigley C, Lleó A, Martinez-Lage P, Mecocci P, Meersmans K, Molinuevo JL, Peyratout G, Popp J, Richardson J, Sala I, Scheltens P, Streffer J, Soininen H, Tainta-Cuezva M, Teunissen C, Tsolaki M, Vandenberghe R, Visser PJ, Vos S, Wahlund LO, Wallin A, Westwood S, Zetterberg H, Lovestone S, Morgan BP; Annex: NIMA-Wellcome Trust Consortium for 
Neuroimmunology of Mood Disorders and Alzheimer's Disease. Inflammatory biomarkers in Alzheimer's disease plasma. Alzheimers Dement. 2019 Jun;15(6):776-787.

11. McAfoose J, Baune BT. Evidence for a cytokine model of cognitive function. Neuroscience and Biobehavioral Reviews. 2009; 15(6):776-787.

12. Scherer EBS, Loureiro SO, Vuaden FC, da Cunha AA, Schmitz F, Kolling J, et al. Mild Hyperhomocysteinemia Increases Brain Acetylcholinesterase and Proinflammatory Cytokine Levels in Different Tissues. Mol Neurobiol. 2014;50(2):589-96.

13. Wu S, Deng F, Wei H, Huang J, Wang H, Shima M, et al. Chemical constituents of ambient particulate air pollution and biomarkers of inflammation, coagulation and homocysteine in healthy adults: A prospective panel study. Part Fibre Toxicol. 2012;9:49.
14. Durga J, van Boxtel MP, Schouten EG, Kok FJ, Jolles J, Katan MB, et al. Effect of 3-year folic acid supplementation on cognitive function in older adults in the FACIT trial: a randomised, double blind, controlled trial. Lancet. 2007;369(9557):208-16.

15. Huijbers W, Mormino EC, Schultz AP, Wigman S, Ward AM, Larvie $M$, et al. Amyloid- $\beta$ deposition in mild cognitive impairment is associated with increased hippocampal activity, atrophy and clinical progression. Brain. 2015;138(Pt 4):1023-35.

16. Lazarov $O$, Hollands $C$. Hippocampal neurogenesis: Learning to remember. Progress in Neurobiology. 2016;138-140:1-18.

17. Marsland AL, Gianaros PJ, Abramowitch SM, Manuck SB, Hariri AR. Interleukin-6 Covaries Inversely with Hippocampal Grey Matter Volume in Middle-Aged Adults. Biol Psychiatry. 2008;64(6):484-490.

Conflict of interest: none declared Financial support: none declared 